\title{
Corrigendum: CAR T Cells Targeting the Tumor MUC1 Glycoprotein Reduce Triple-Negative Breast Cancer Growth
}

\section{OPEN ACCESS}

Approved by:

Frontiers Editorial Office,

Frontiers Media SA, Switzerland

*Correspondence:

Pinku Mukherjee

pmukher@uncc.edu

Specialty section: This article was submitted to

Cancer Immunity and

Immunotherapy,

a section of the journal

Frontiers in Immunology

Received: 12 November 2020

Accepted: 13 November 2020

Published: 07 December 2020

Citation:

Zhou R, Yazdanifar M, Roy $L D$, Whilding LM, Gavrill A, Maher J and Mukherjee $P$ (2020) Corrigendum: CAR T Cells Targeting the Tumor MUC1 Glycoprotein Reduce TripleNegative Breast Cancer Growth

Front. Immunol. 11:628776. doi: 10.3389/fimmu.2020.628776

\author{
Ru Zhou ${ }^{1}$, Mahboubeh Yazdanifar ${ }^{1}$, Lopamudra Das Roy ${ }^{1}$, Lynsey M. Whilding ${ }^{2}$, \\ Artemis Gavrill ${ }^{2}$, John Maher ${ }^{2}$ and Pinku Mukherjee ${ }^{1 *}$ \\ ${ }_{1}^{1}$ Department of Biological Sciences, University of North Carolina at Charlotte, Charlotte, NC, United States, ${ }^{2}$ School of \\ Cancer and Pharmaceutical Sciences, King's College London, Guy's Hospital Campus, London, United Kingdom
}

Keywords: triple-negative breast cancer, immunotherapy, MUC28z CAR T cells, MUC1, TAB004

\section{A Corrigendum on}

CAR T Cells Targeting the Tumor MUC1 Glycoprotein Reduce Triple-Negative Breast Cancer Growth

by Zhou R, Yazdanifar M, Roy LD, Whilding LM, Gavrill A, Maher J and Mukherjee P (2019). Front. Immunol. 10:1149. doi: 10.3389/fimmu.2019.01149

There was an error in the Funding statement. The correct name for the funder is DOD.

In the original article, we neglected to include the funder DOD, W81XWH-18-1-0711 to Ru Zhou, Mahboubeh Yazdanifar, Lopamudra Das Roy, Lynsey M. Whilding, Artemis Gavrill, John Maher, and Pinku Mukherjee.

The authors apologize for these errors and state that this does not change the scientific conclusions of the article in any way. The original article has been updated.

Copyright () 2020 Zhou, Yazdanifar, Roy, Whilding, Gavrill, Maher and Mukherjee. This is an open-access article distributed under the terms of the Creative Commons Attribution License (CC BY). The use, distribution or reproduction in other forums is permitted, provided the original author(s) and the copyright owner(s) are credited and that the original publication in this journal is cited, in accordance with accepted academic practice. No use, distribution or reproduction is permitted which does not comply with these terms. 